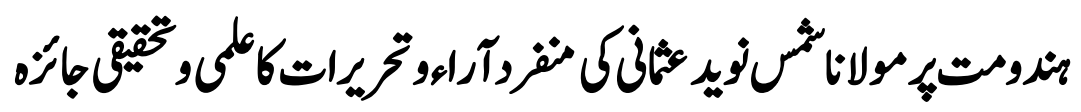

\title{
A Critical Study of Maulana Shams Naved Usmani's Rare Thoughts and Writings about Hinduism
}

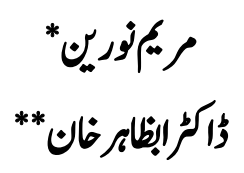

Abstract

Acharya $^{1}$ Maulana Shams Naved Usmani's was an important thinker (mufakkir) and researcher of his times. He had extensive knowledge regarding Hindusim. He was a passionate advocate of Hindu-Muslim interfaith dialogue, spawning a new trend in India Muslim literary and activist circles. Maulana chartered a new course in Islamic literature in India, seeking to combine a commitment to inter-faith dialogue with what seems to have been his principal mission, that of Da'wah, or inviting others to Islam.

Muslim understanding for the first time has highlighted an aspect regarding Hinduism where hindu sacred books are read in contrast with quran and hadith and scattered facts about Islam are collected and presented to manifest the true picture of Islam. Though in the past too, there existed to some extent the proof in Hindu sacred texts regarding the truth of Islam, this trend increased after Maulana's work in this context. He explained the meaning and interpretation of many important Hindu views in the light if Islam. For this purpose, he also used translated texts, and sayings of sufis besides Quran and hadith. So, this study is an attempt to present Usmani's views on understanding Hinduism and critically analyze his views in this regard.

Key Words: Inter-faith, Dialogue, Muslim Understanding, Sacred Books, Maulana Shams Naved Usmani

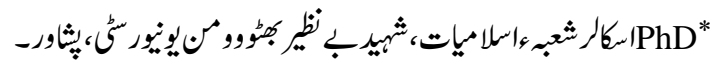






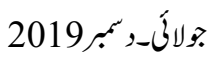

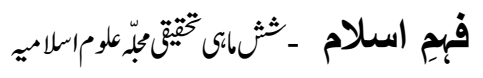

تحارف|ور مطالعاقَزنكى

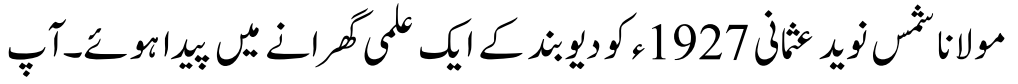

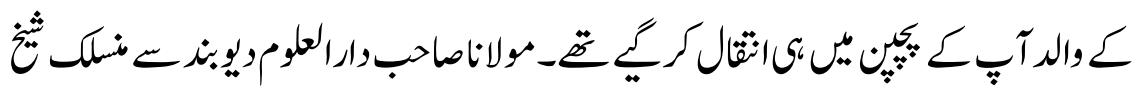

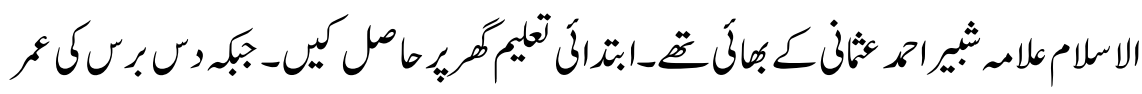

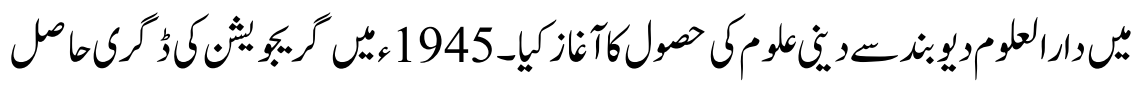

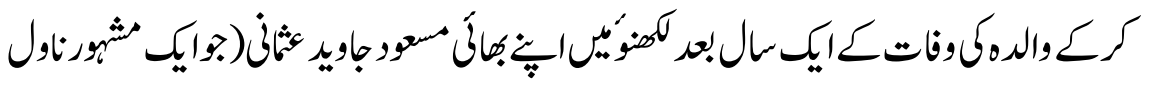

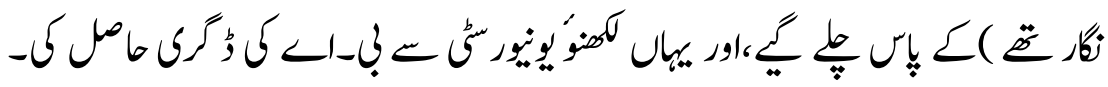

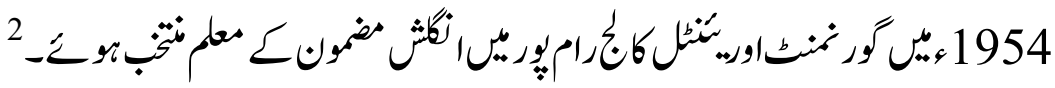

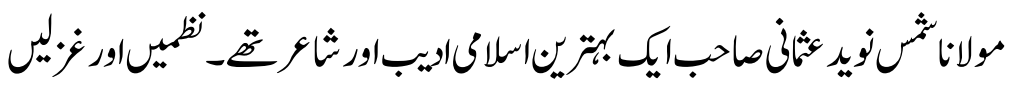

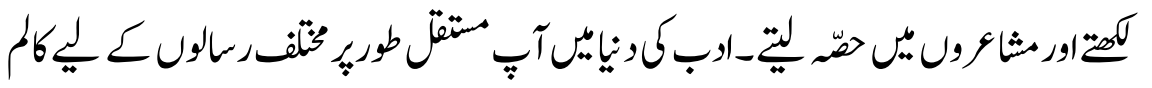

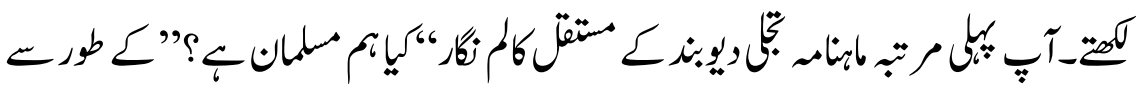

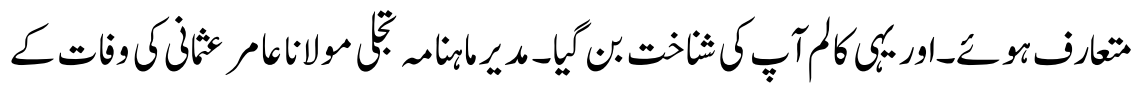

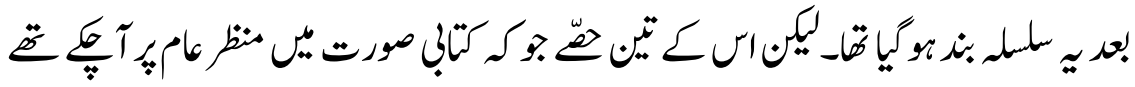

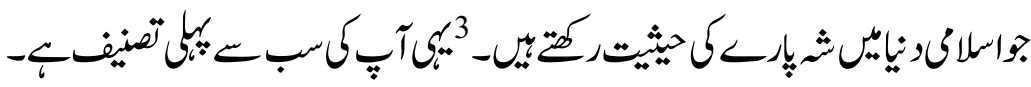

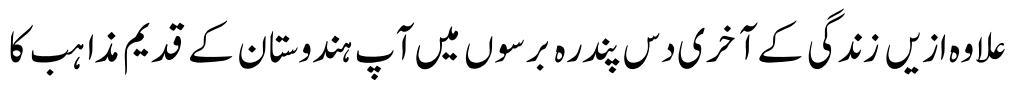

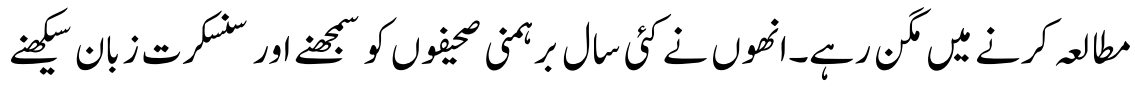

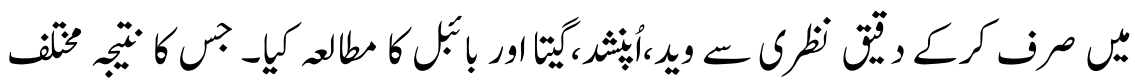

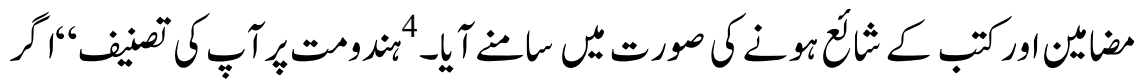

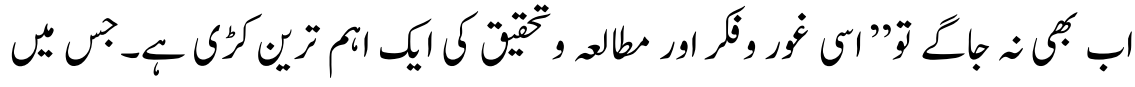

26 


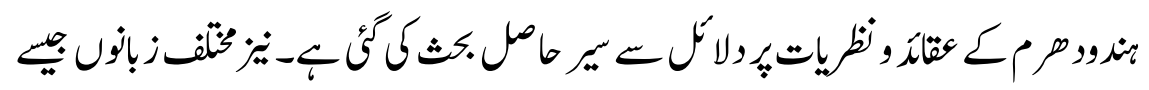

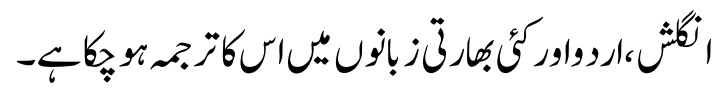

\section{نمجهواسلوباورتيقيقامذ}

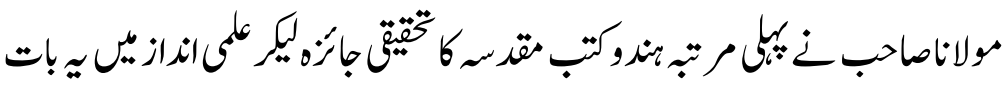

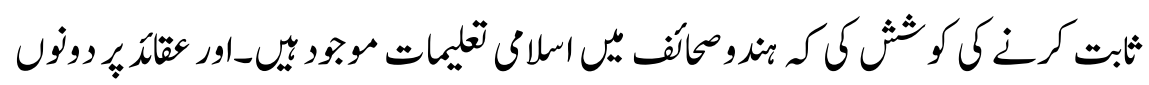

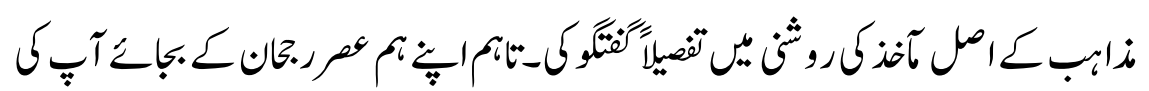

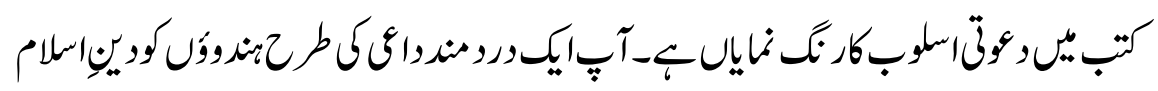

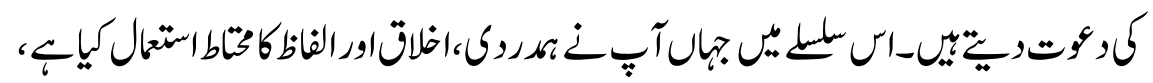

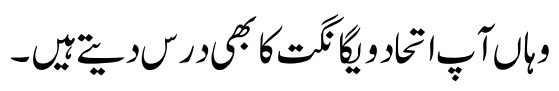

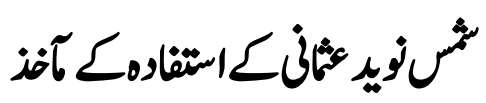

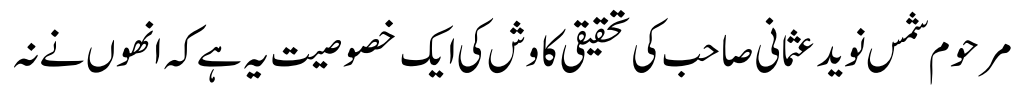

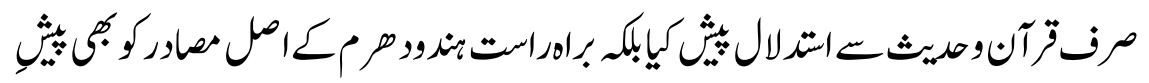

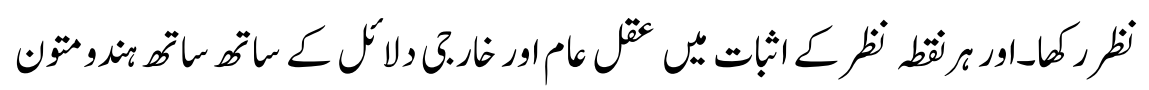

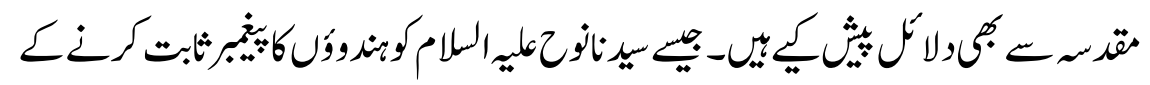

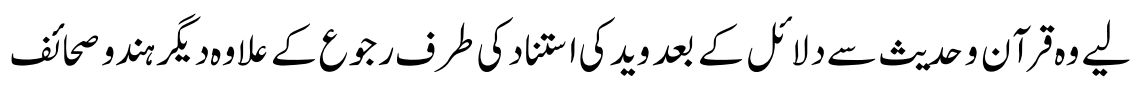

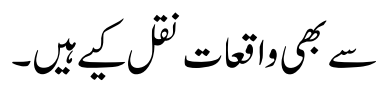

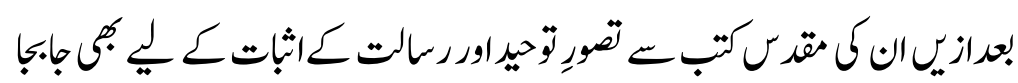

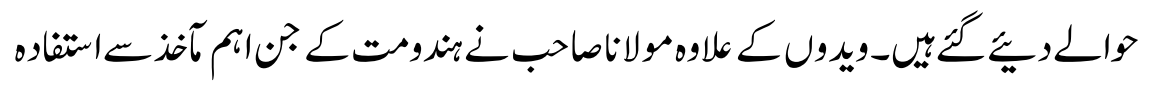

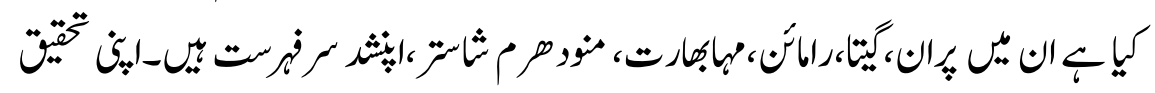




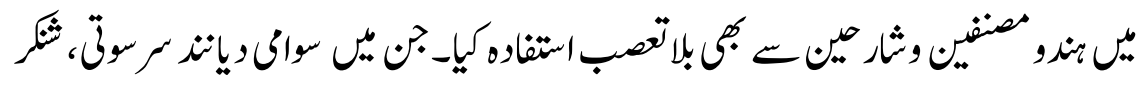

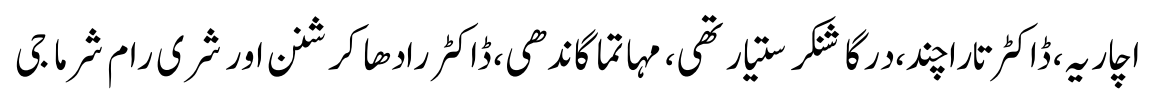
فيرهثالئ-

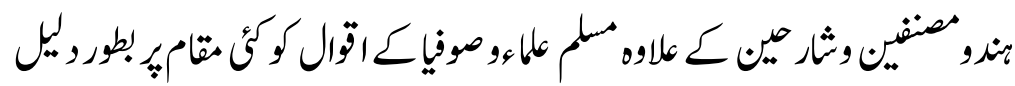

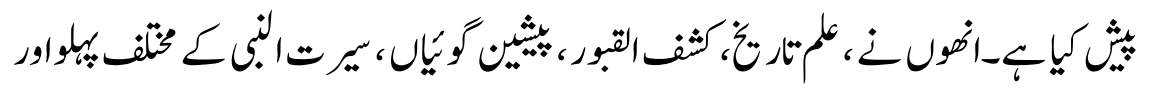

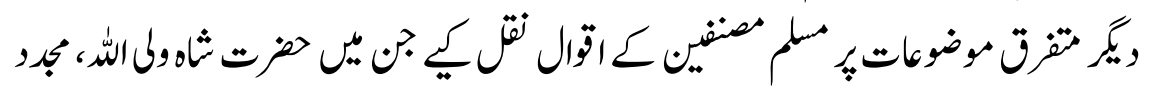

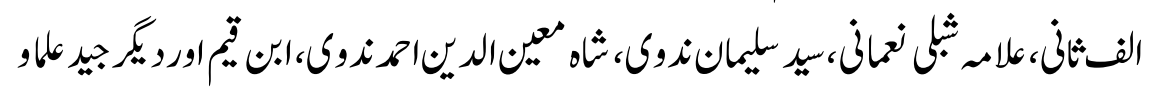

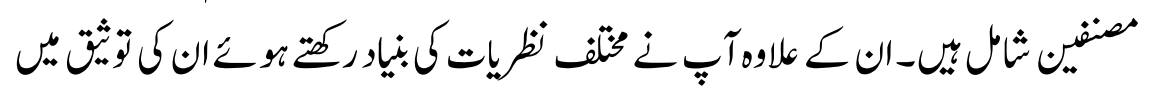

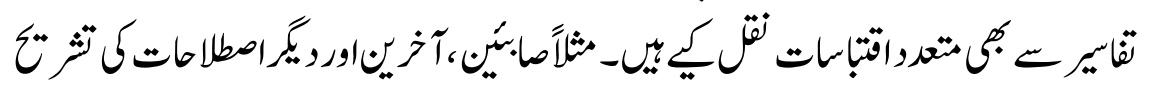



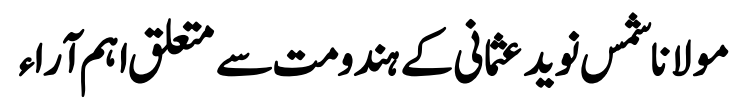

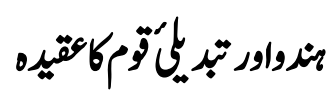

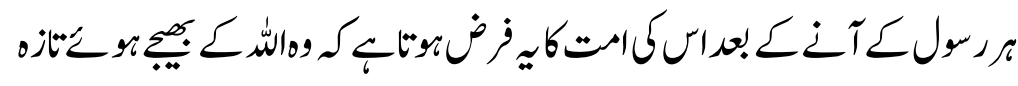

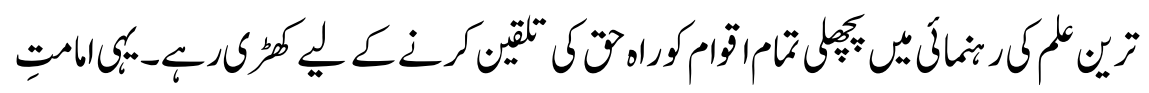

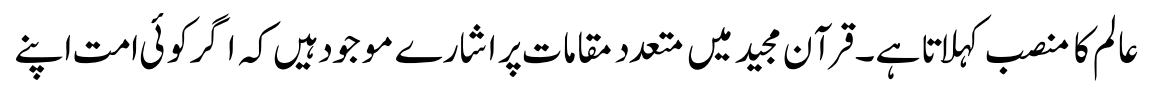

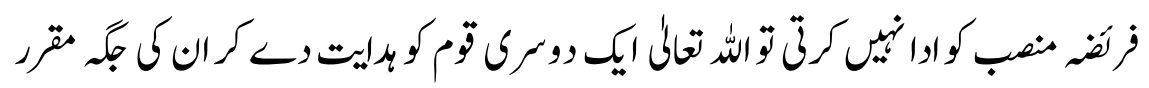

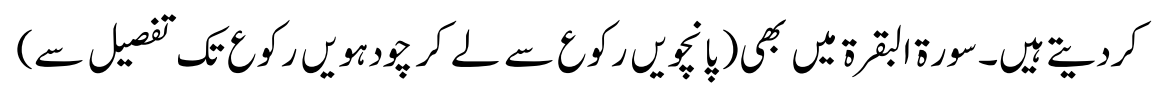

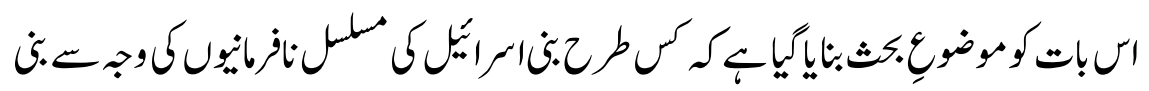

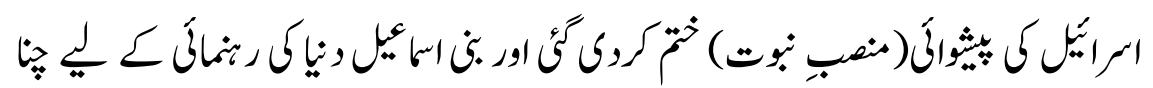

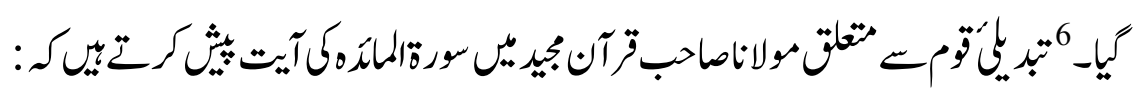






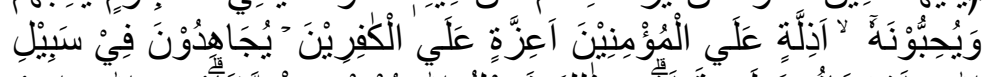

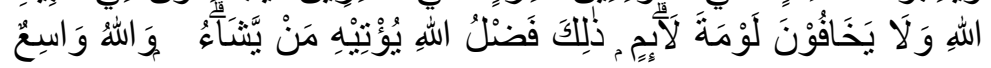

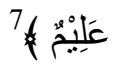

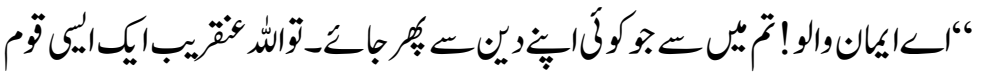

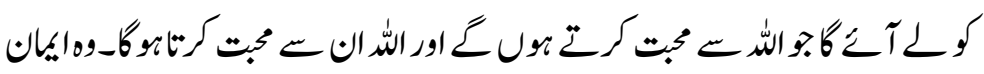

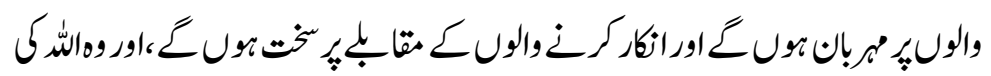

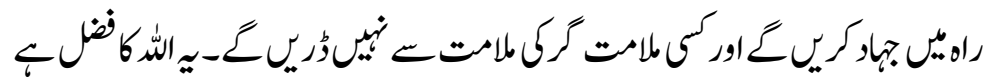

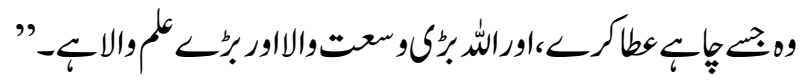

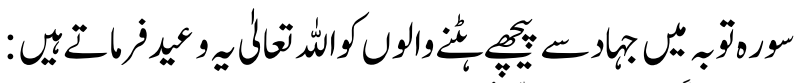

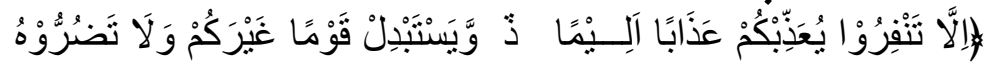

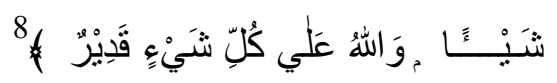

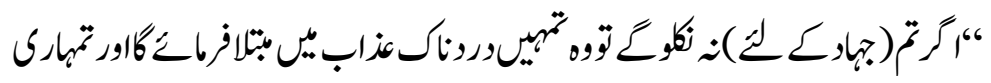

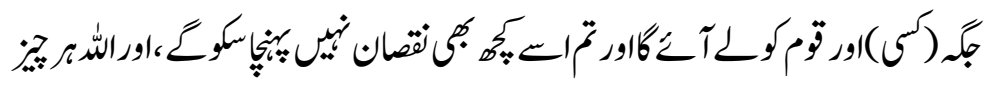

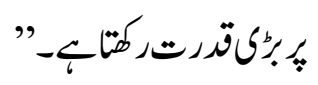

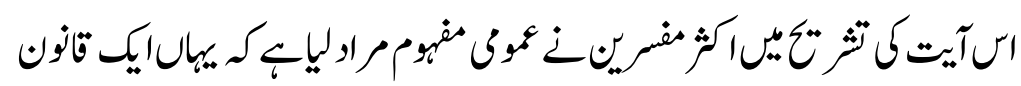

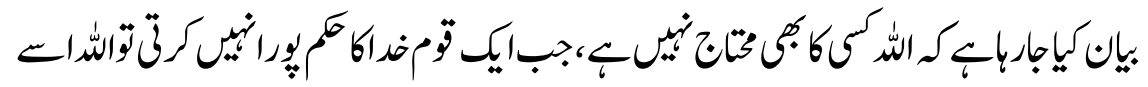

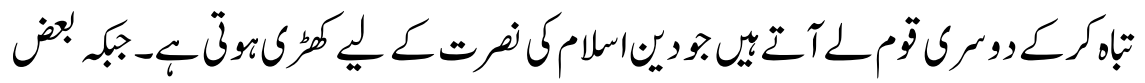

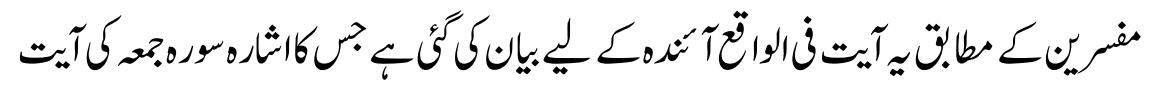

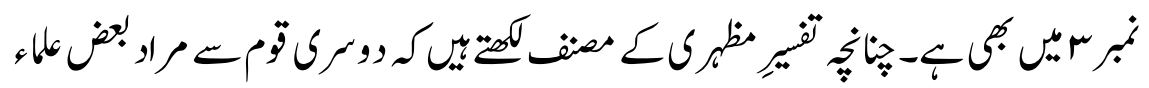

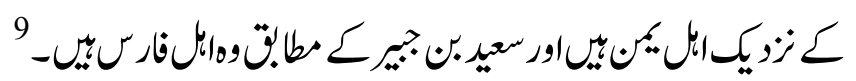

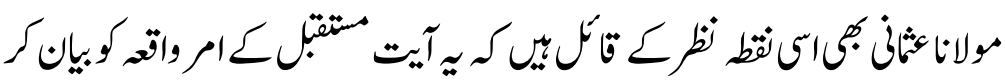

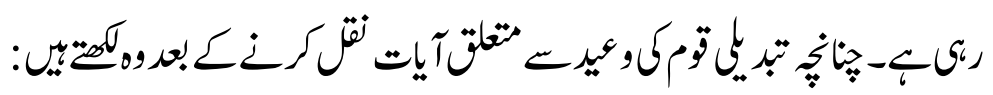




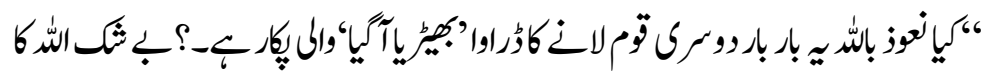

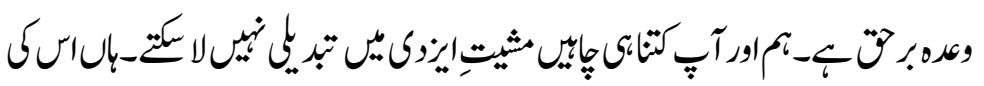

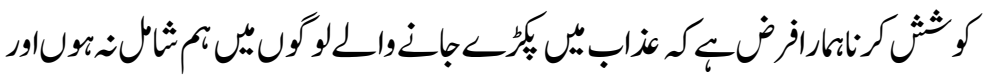

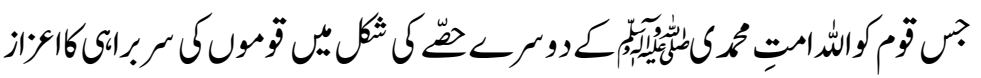

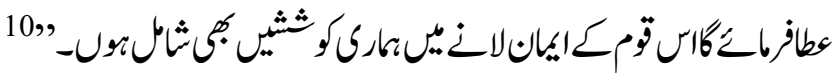

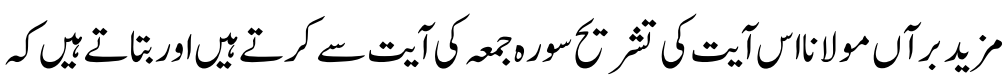

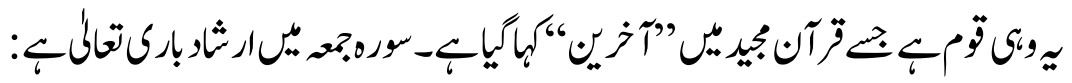

${ }^{11}$

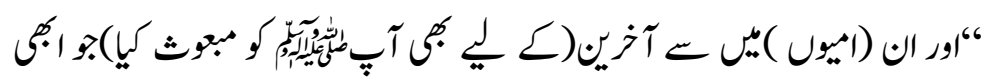

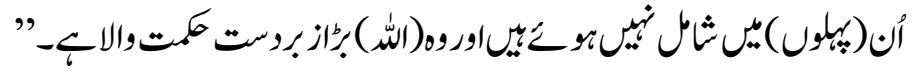

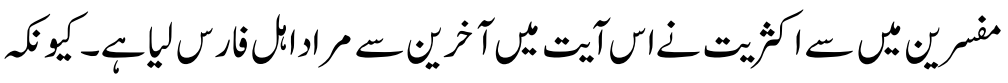

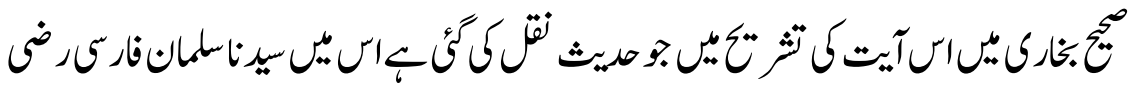

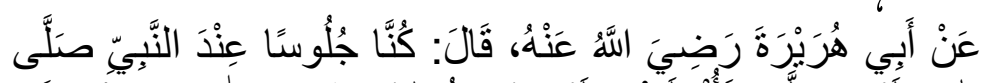

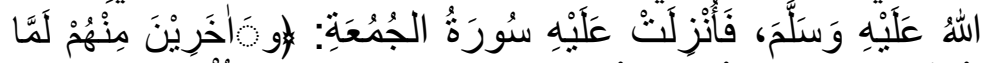

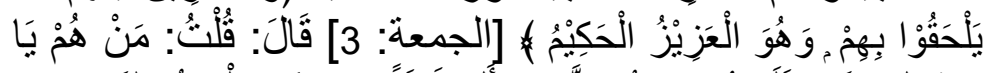

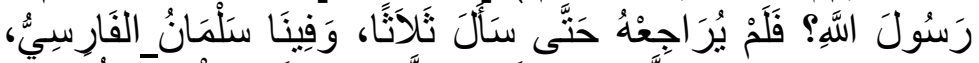

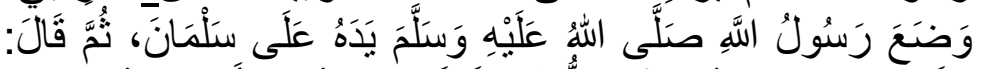

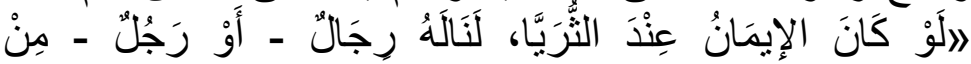
هَوَُ لأَعِ 12

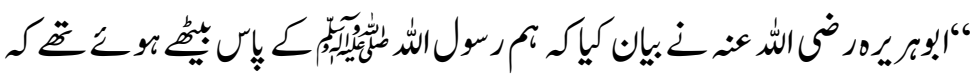

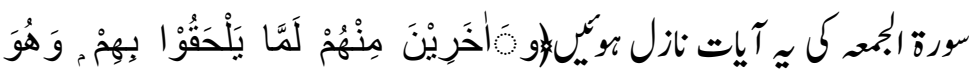

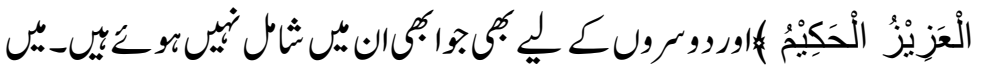




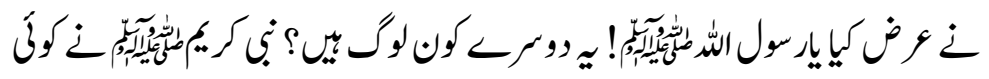

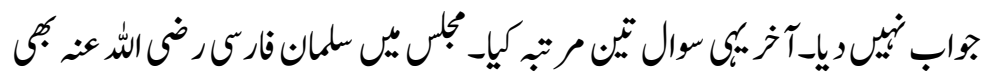

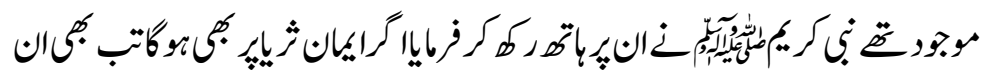

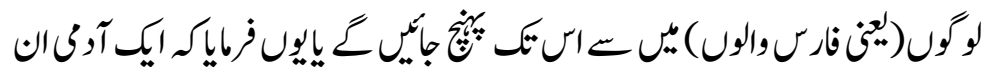

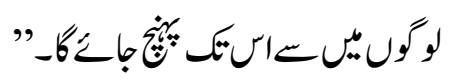

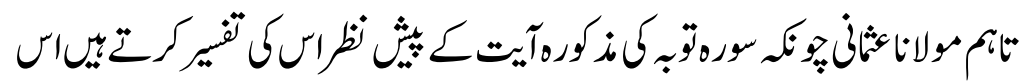

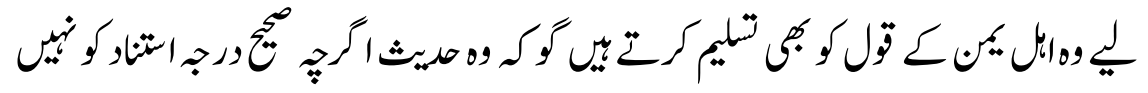



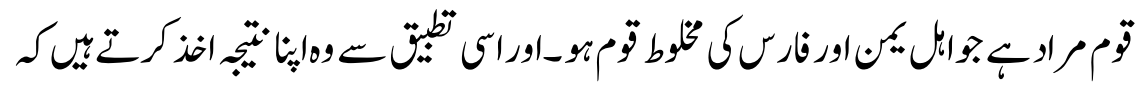

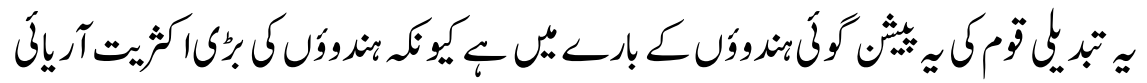

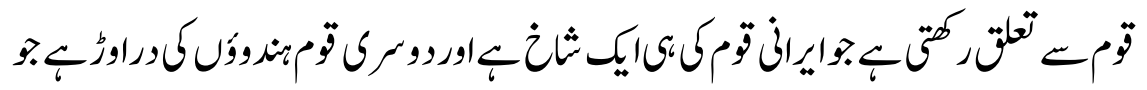

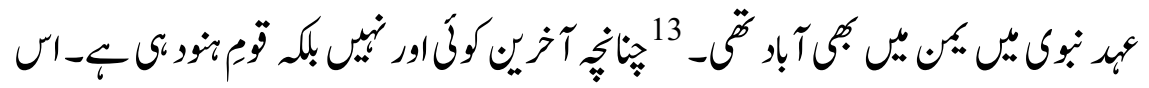

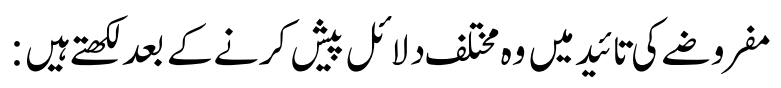

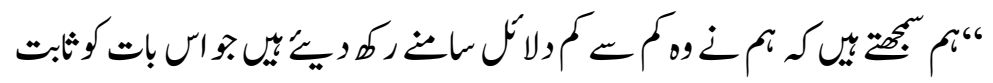

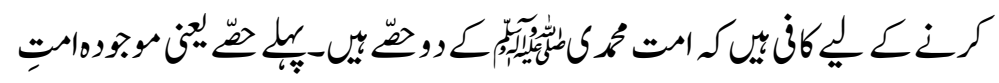

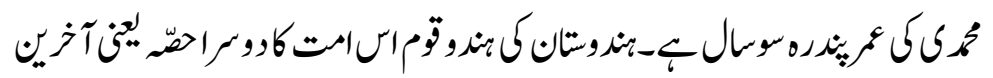

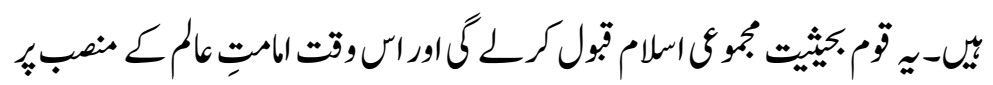

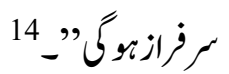

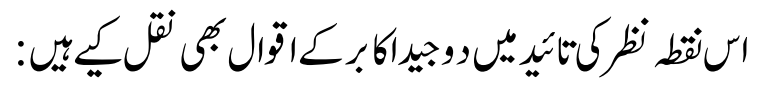

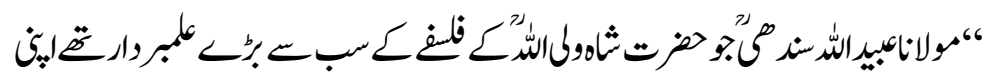

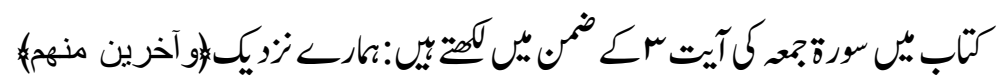




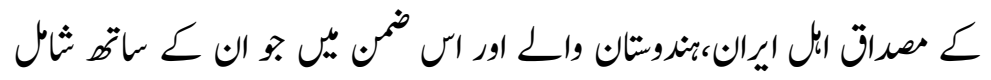

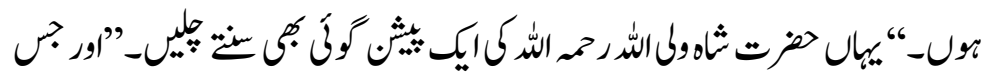

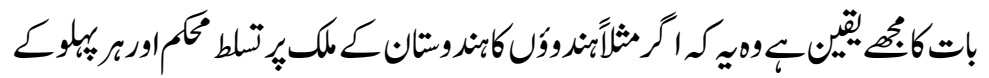

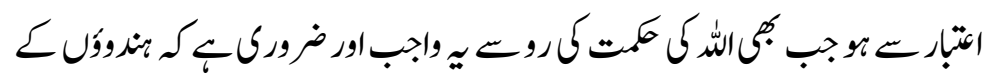

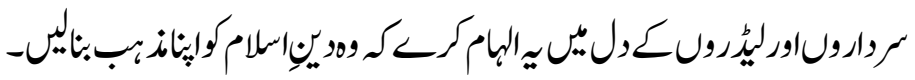

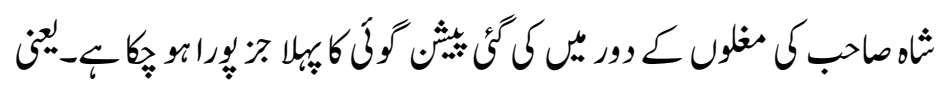

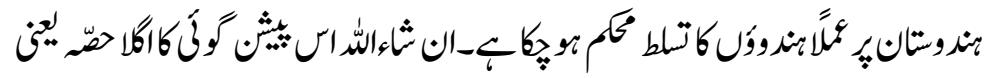

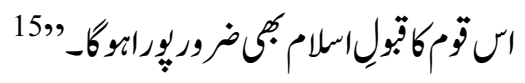

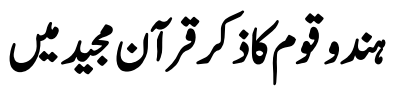

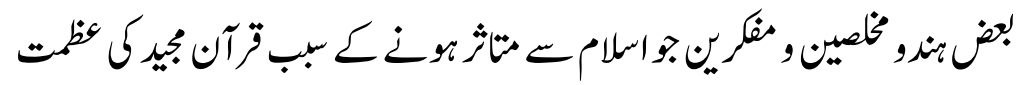

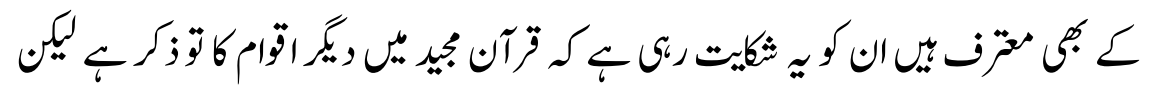

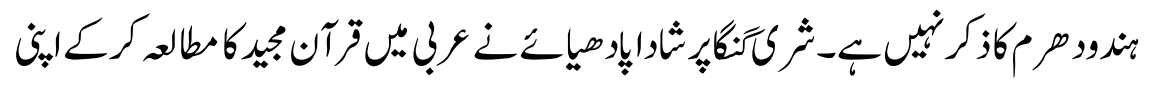

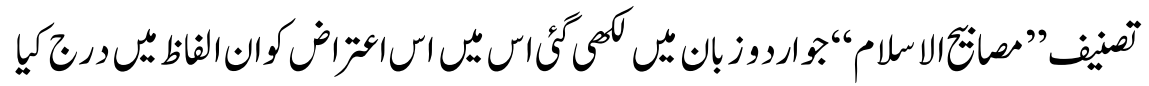

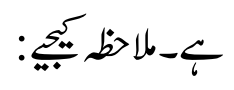

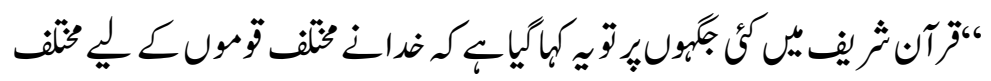

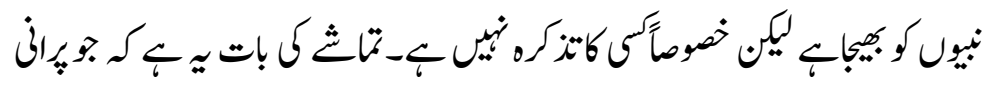

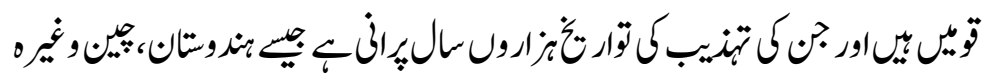

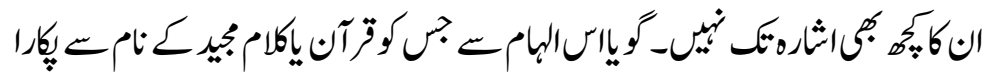

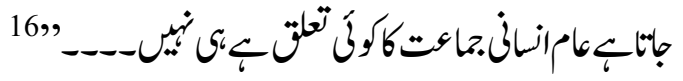




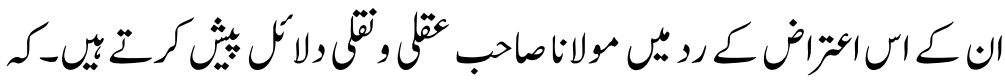

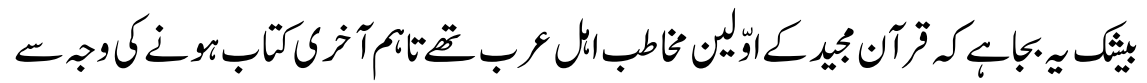



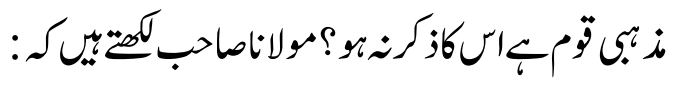



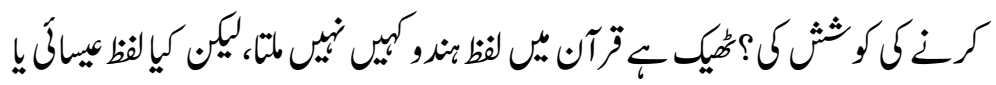

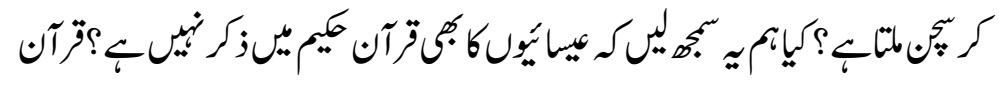

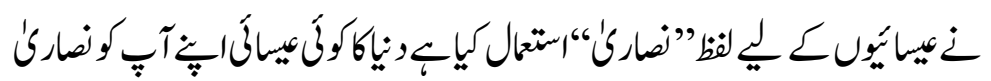

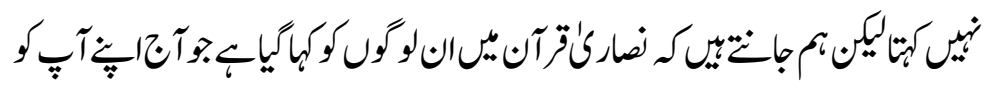

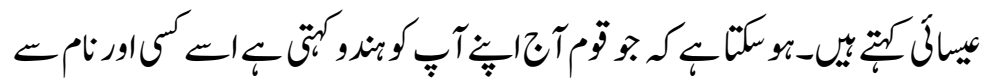

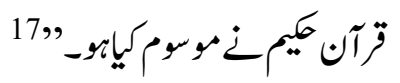

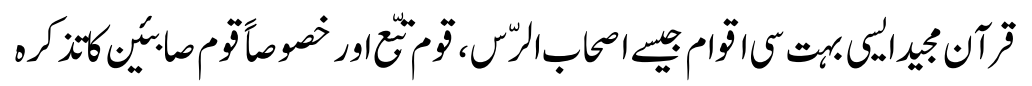

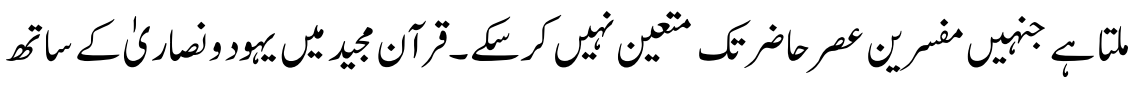

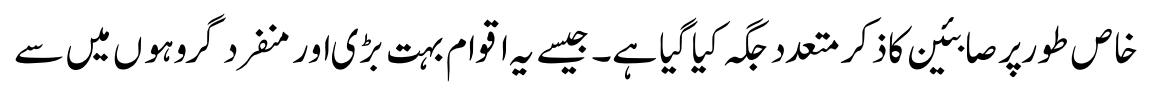

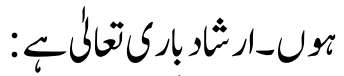

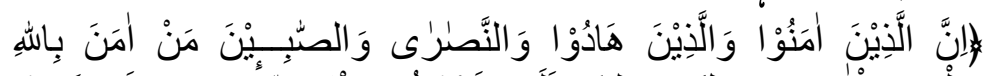

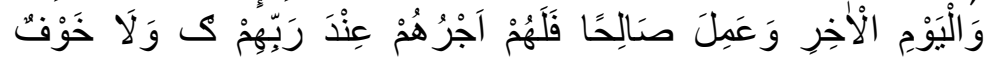

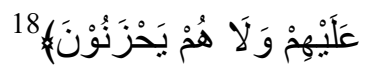



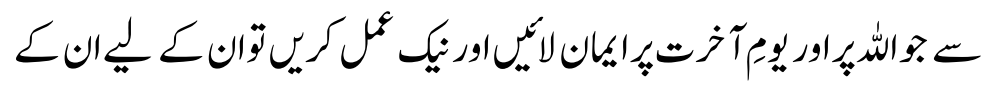

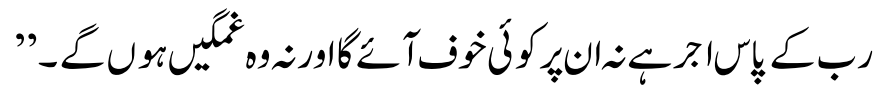


جولأَـــ بمبر2019

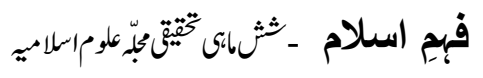

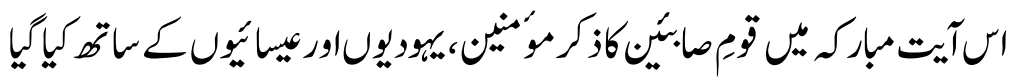

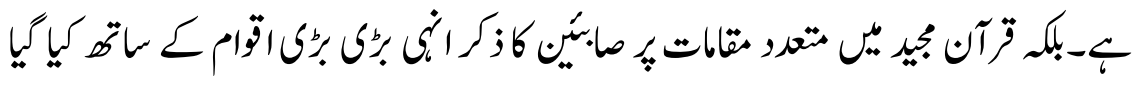

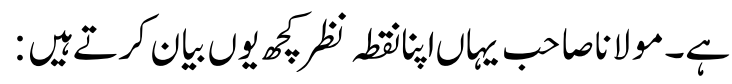



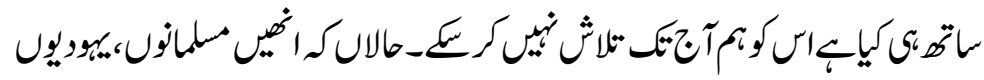

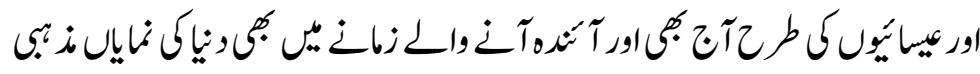

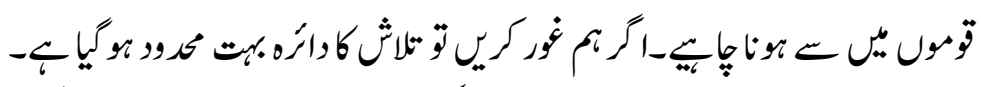

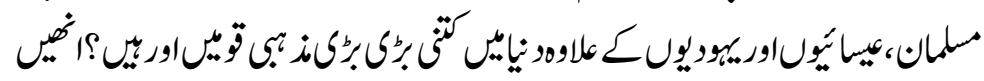

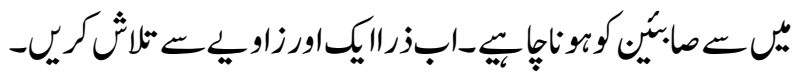



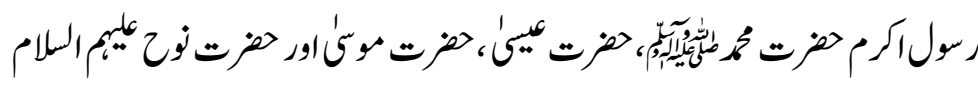

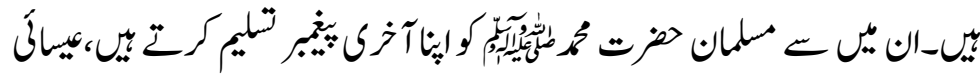

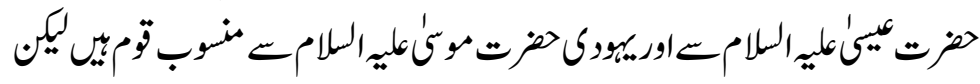

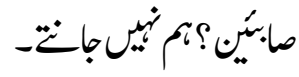

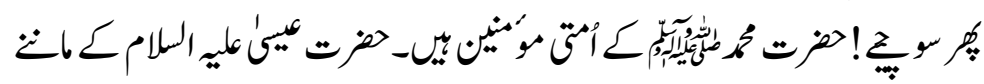

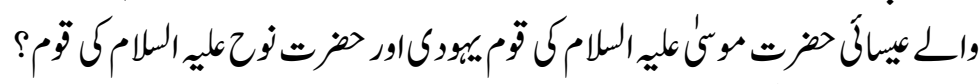

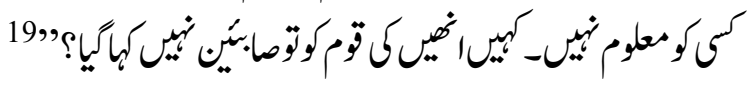

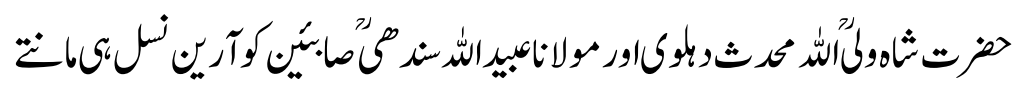



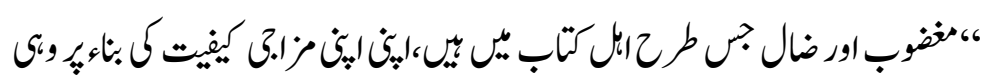

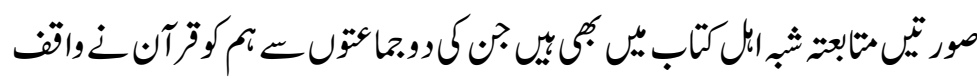

34 




20

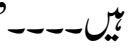

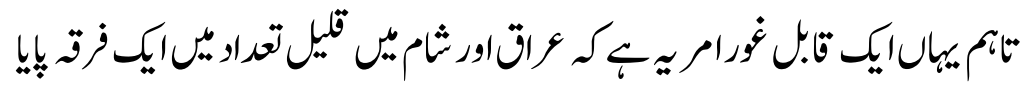

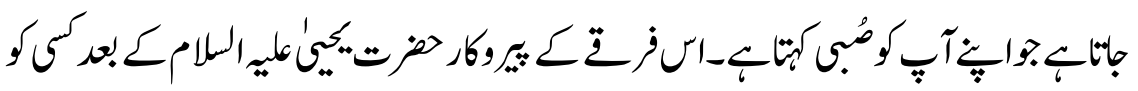

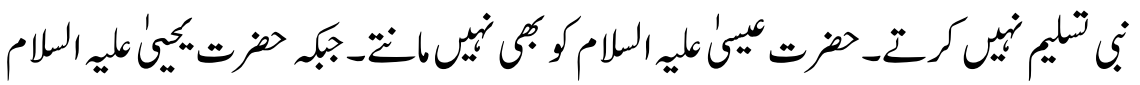



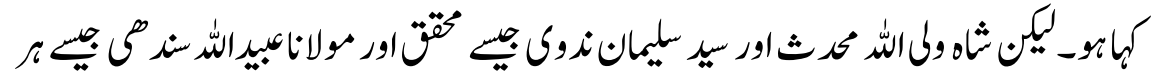



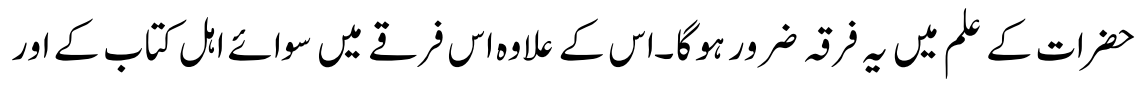

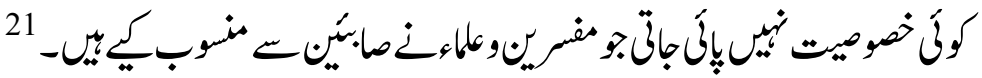

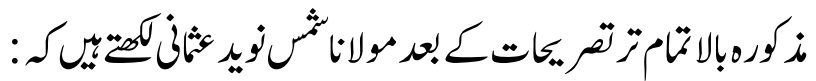

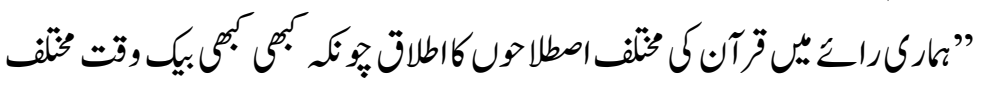

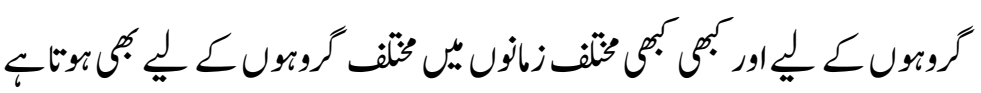



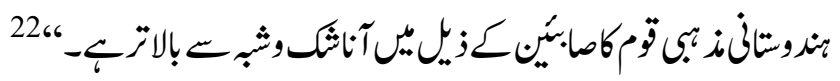

\section{سيزنالوحُاورنور}

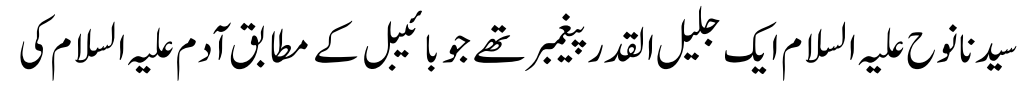

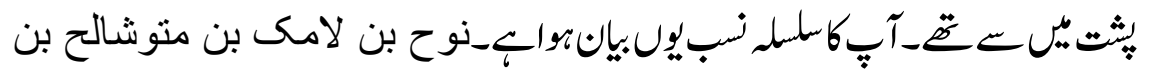

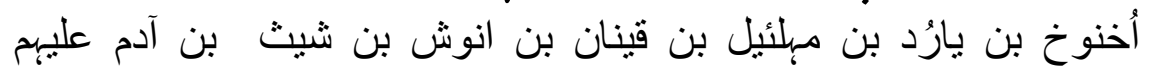

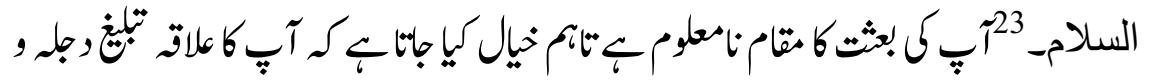


جولأَــ كبمر2019



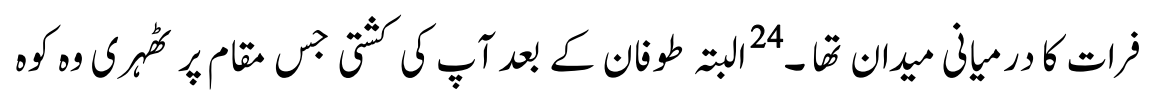

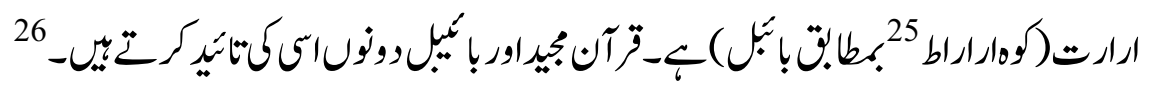

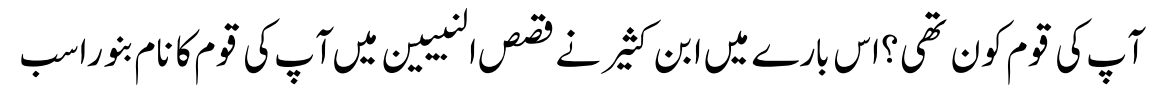

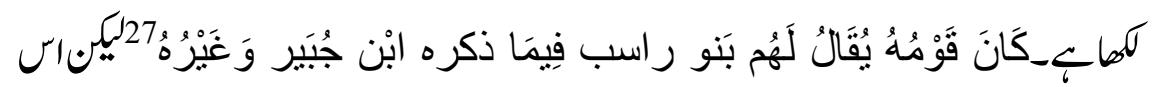

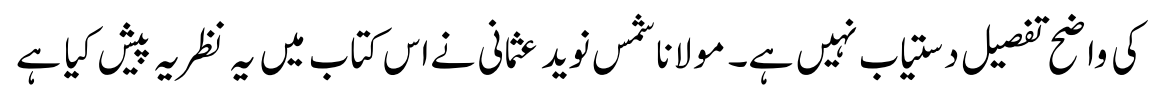

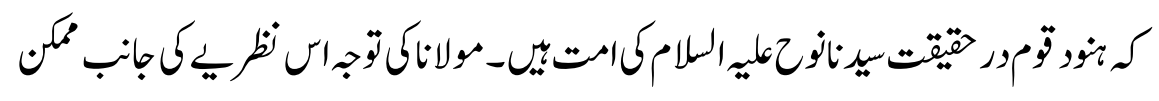

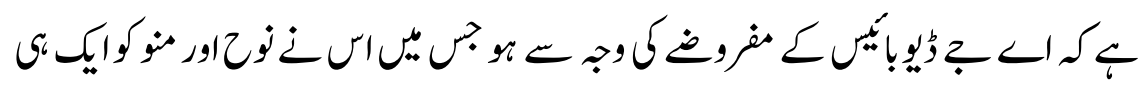

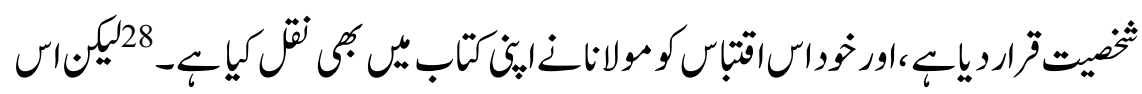

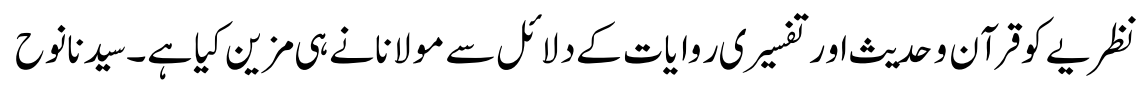

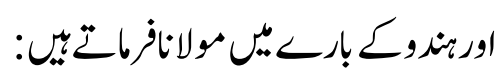

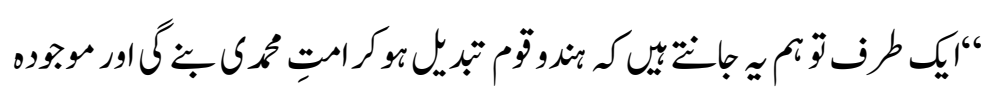

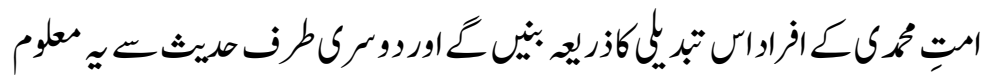

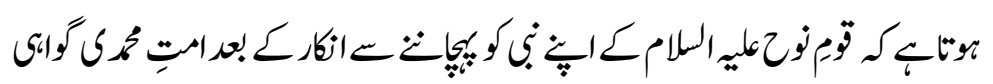

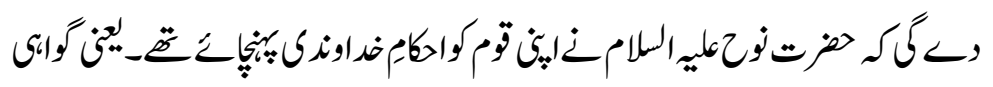

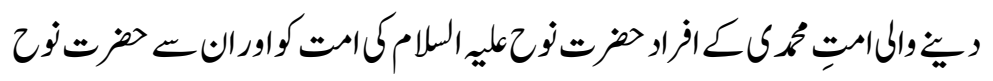



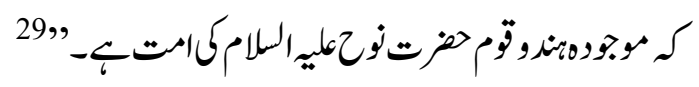

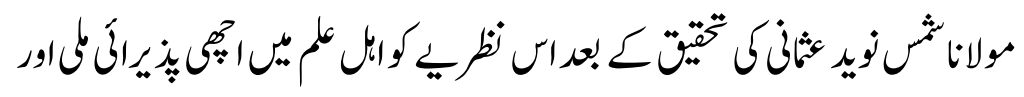



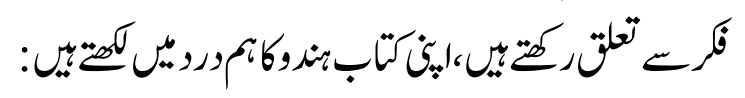

36 


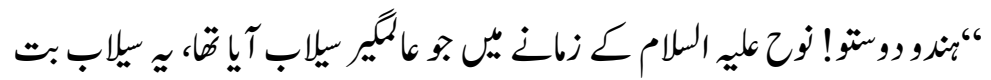



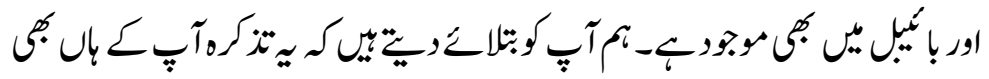

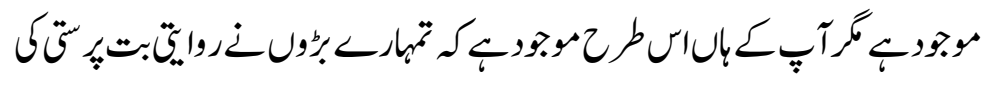



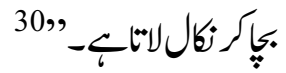

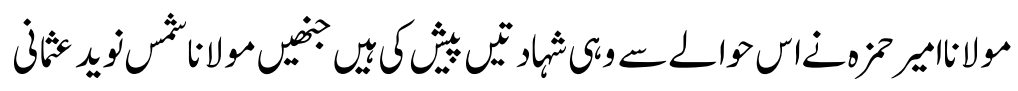

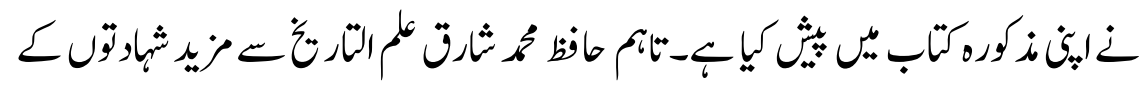

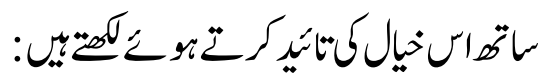

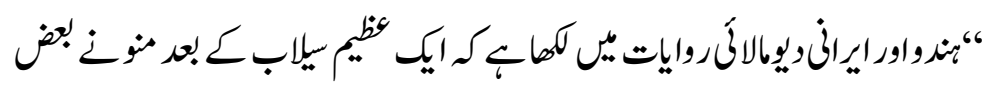

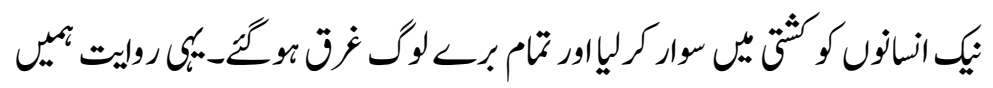



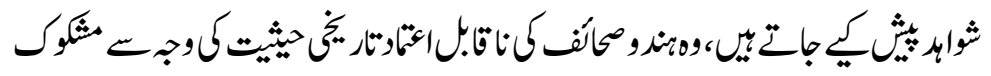

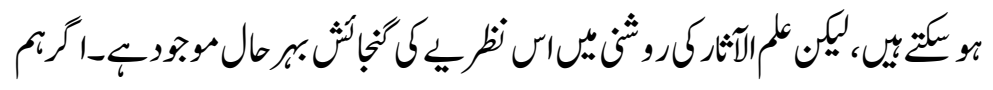



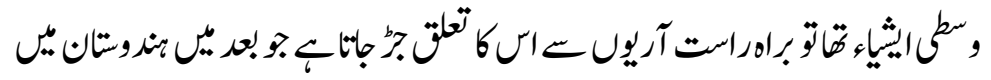



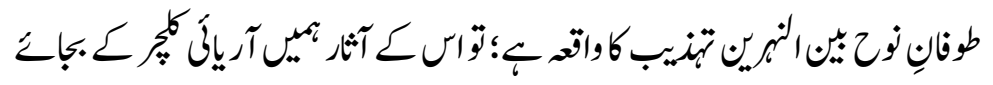

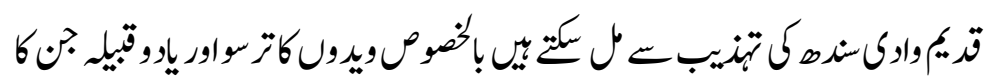

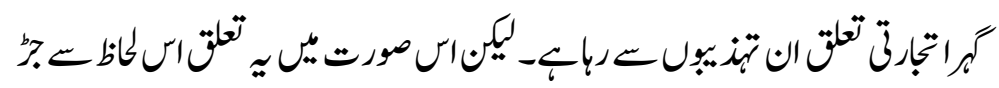

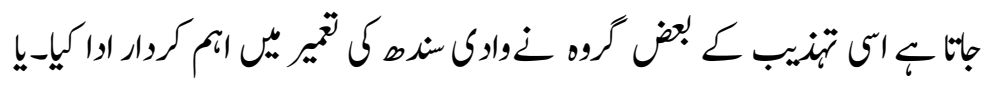




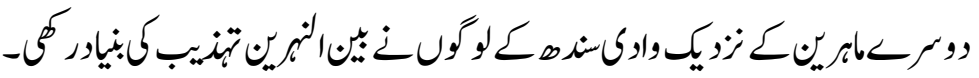

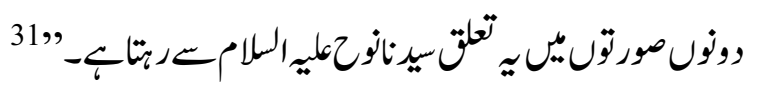



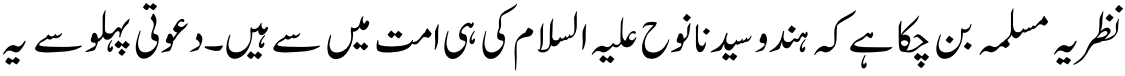

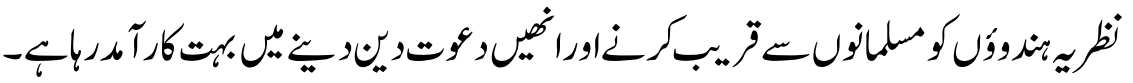

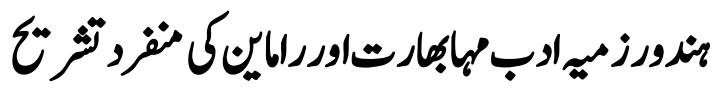



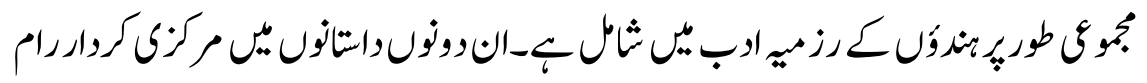

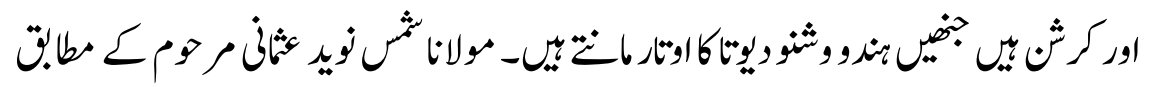

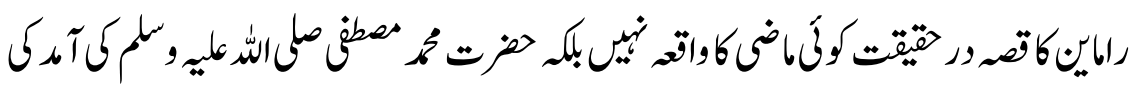

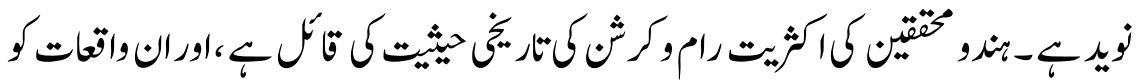

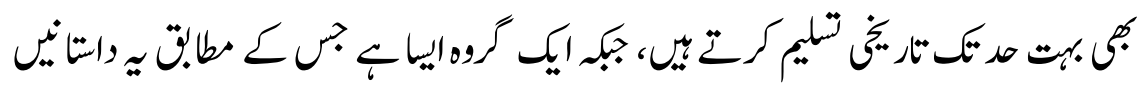

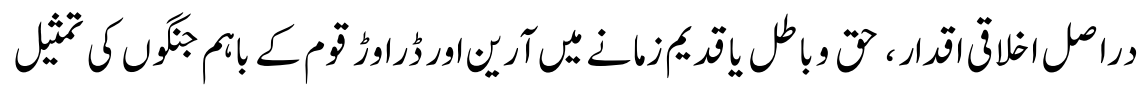

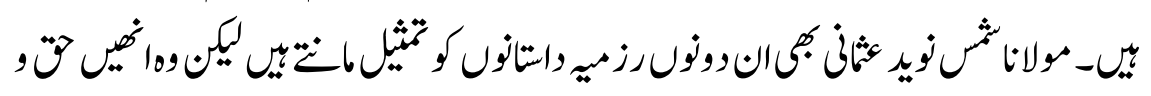

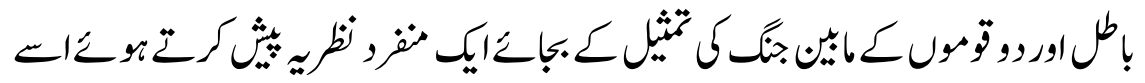

$$
\text { بثارتِنوكس تنير كرتبي: }
$$

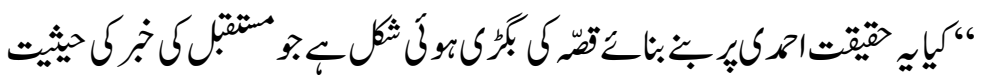

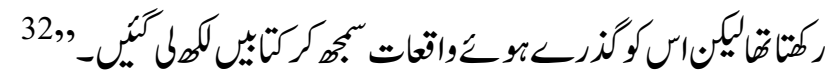




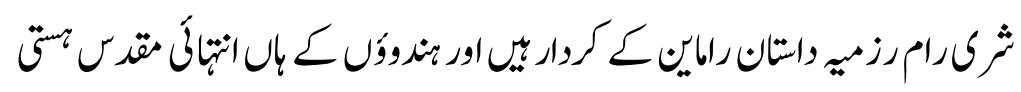

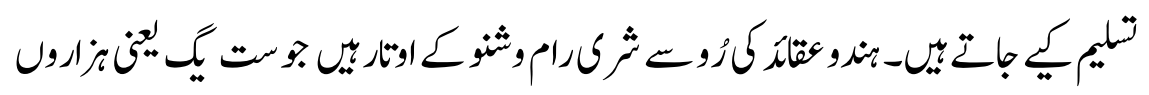

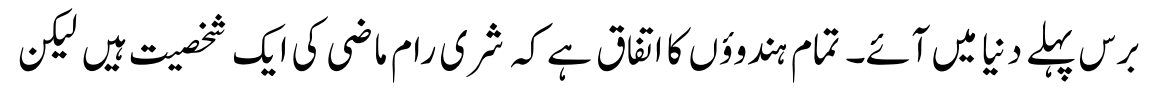

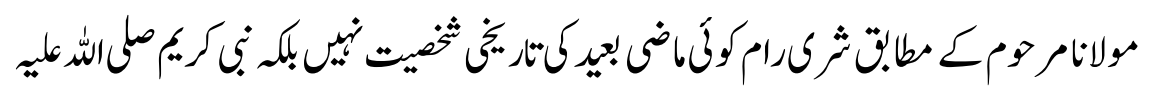

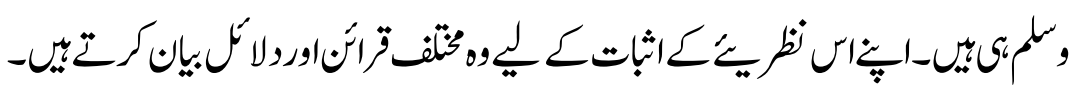

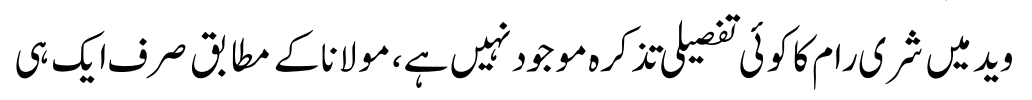

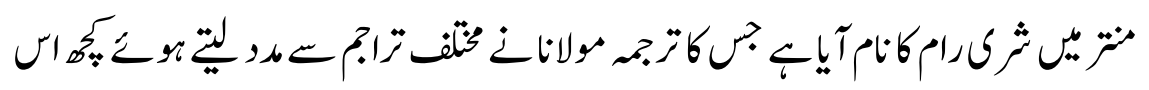
م



$$
\text { بيانكرول-ر" }
$$

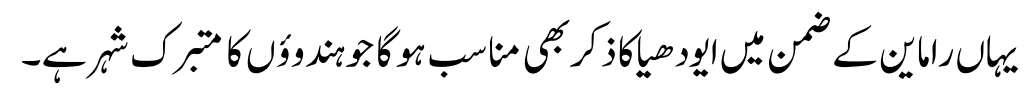



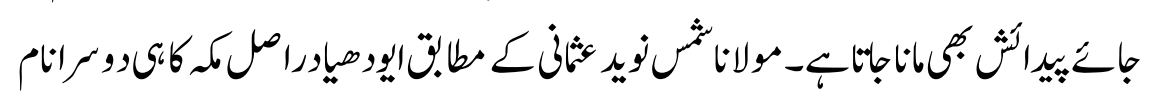

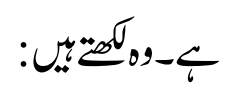

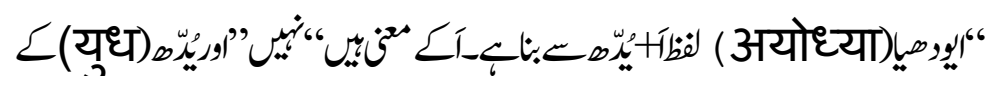

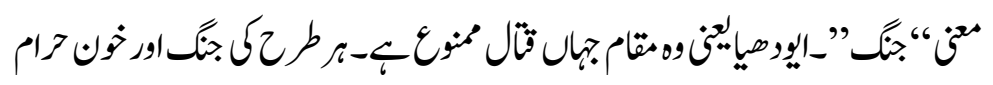



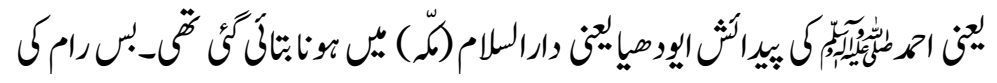

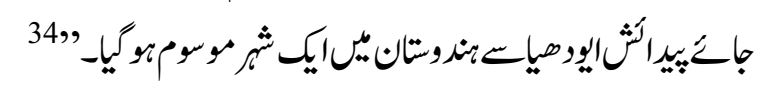

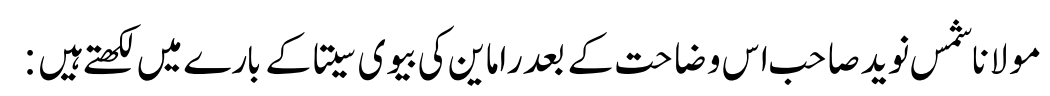




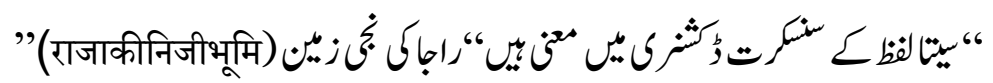

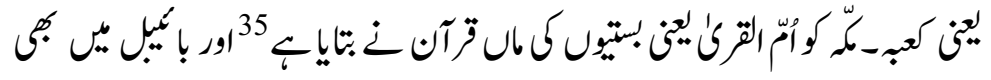

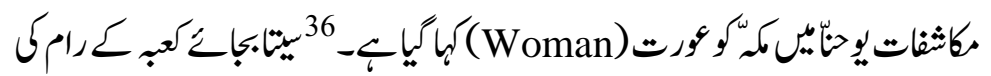

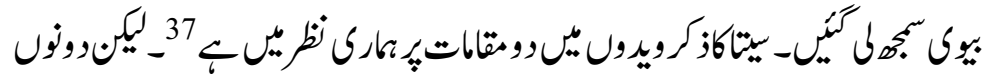

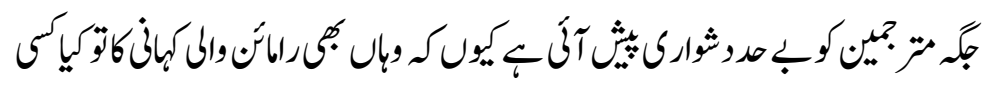

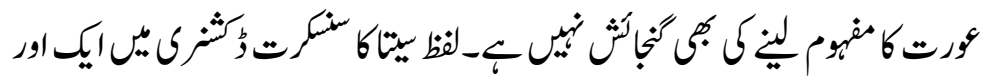

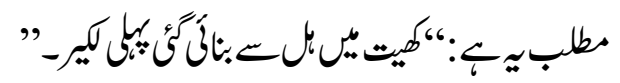

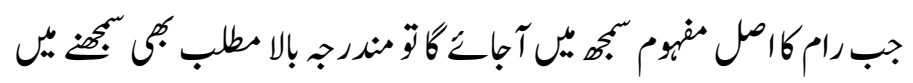

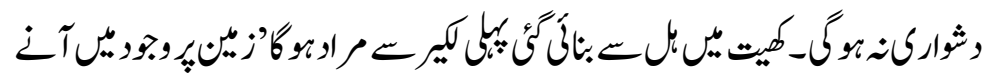

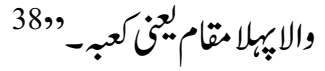



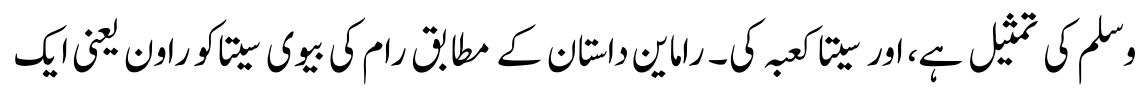

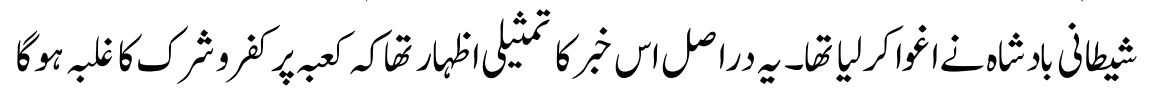

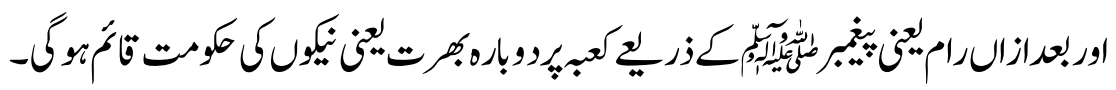

\section{فلام.كث}



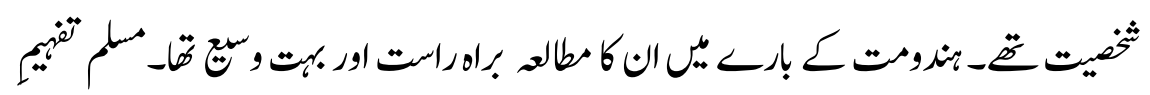

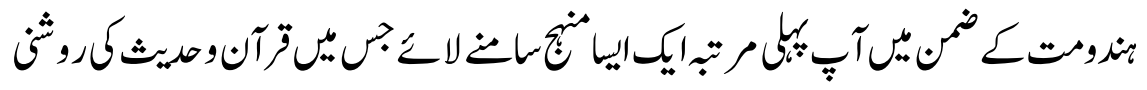

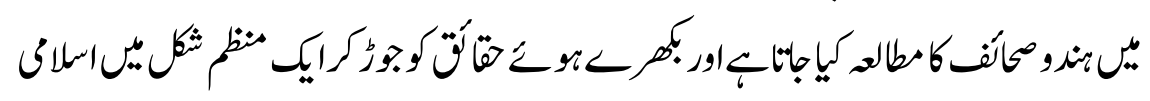




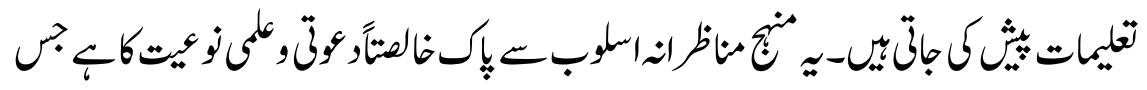

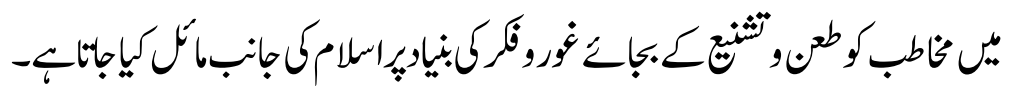

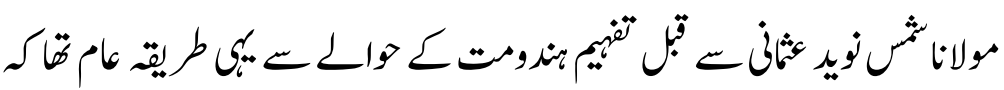

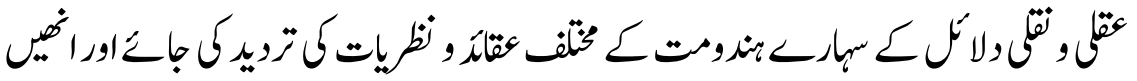

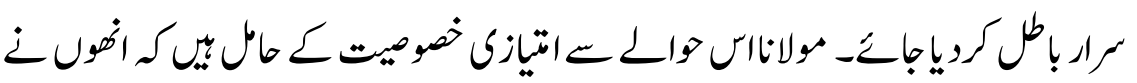

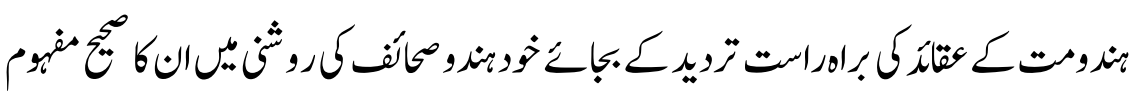

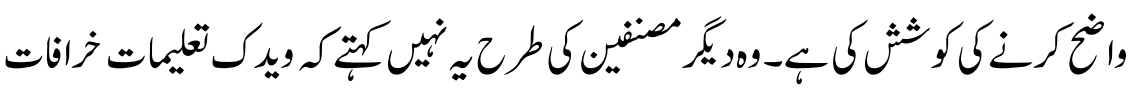

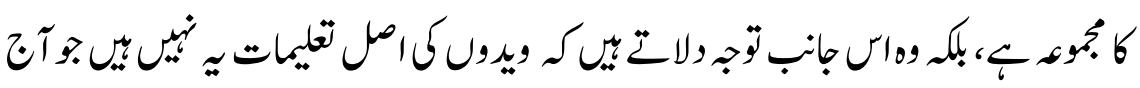

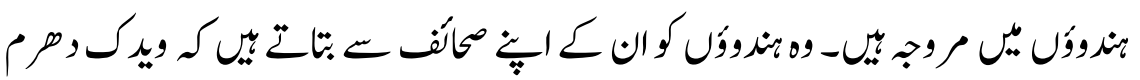

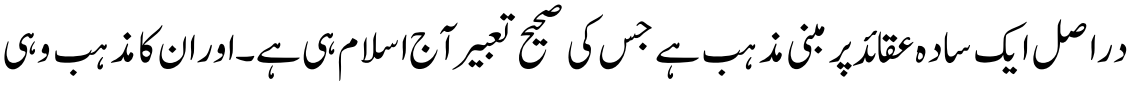

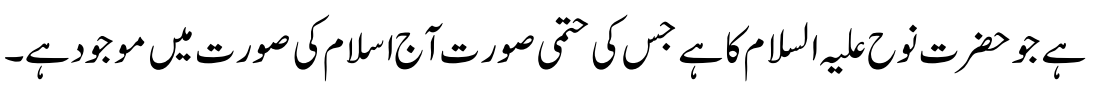
קاثَّومصاور

1 "Acharya and Maulana" are two titles that rarely, if ever, go together. The former is a term generally reserved for Brahmin teachers of Hindu Scriptures, particularly the Vedas. Maulana is a title of respect for an Islamic scholar. Sikand,Yoginder,Muslims in India since 1947:Islamic Perspectives on Inter-Faith Relations, Routledge, 2004, P\#133.

2 http://theamericanmuslim.org/tam.php/features/articles/islam_as_hinduisms fulfilment_acharya_maulana_shams_naved_usmanis_approach(19th nov.2017)

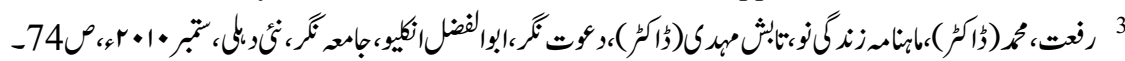
4


5

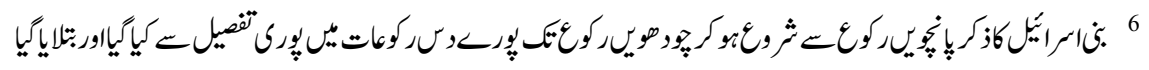






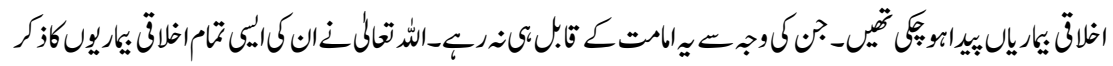



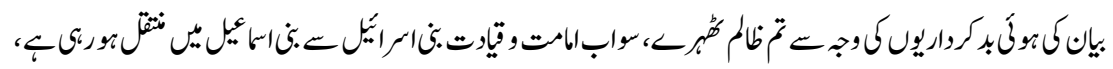

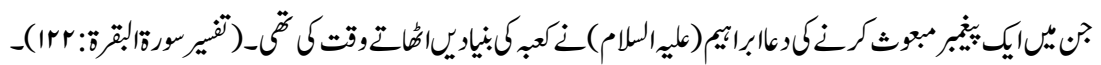

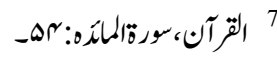

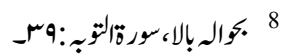

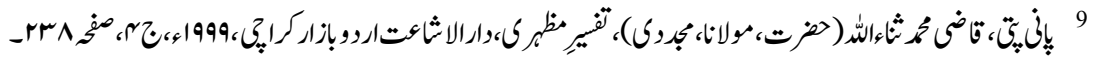

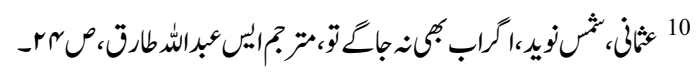

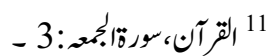

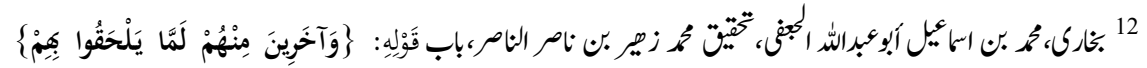



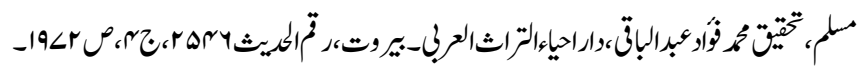

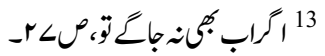

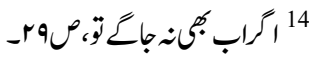

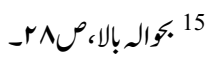

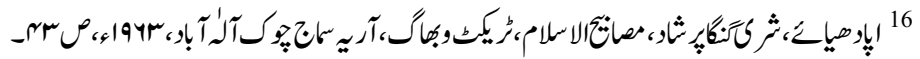

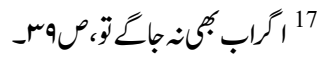

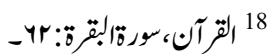

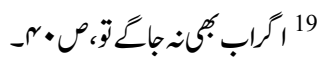





$$
\begin{aligned}
& 22
\end{aligned}
$$

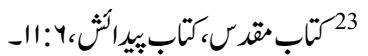

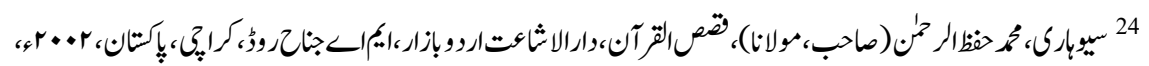



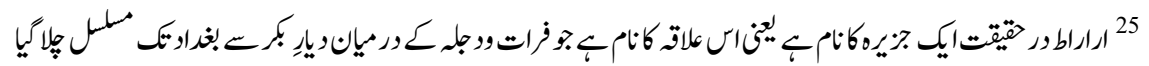

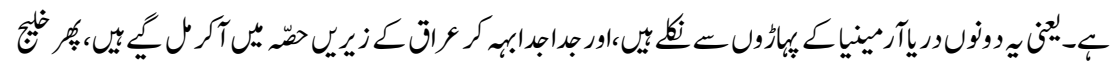




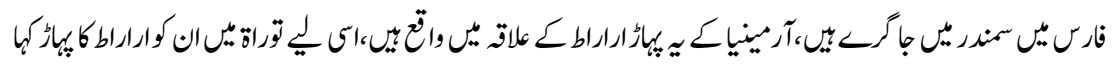

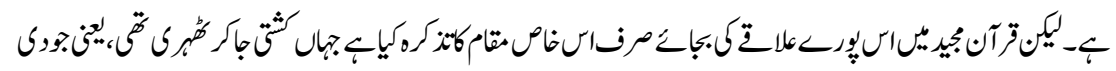

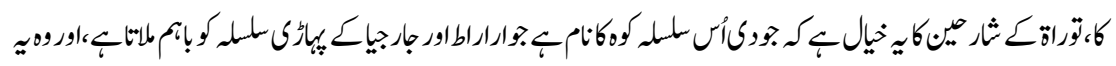

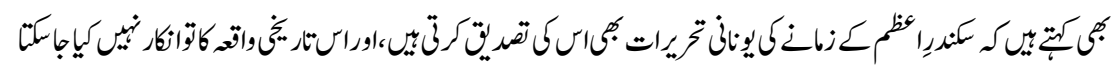

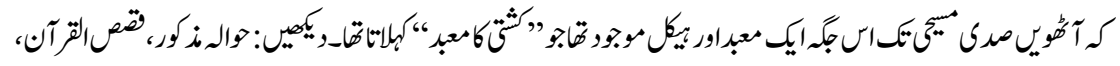

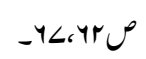

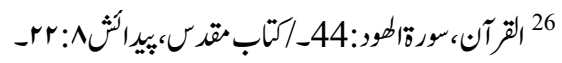

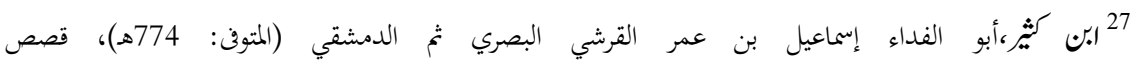

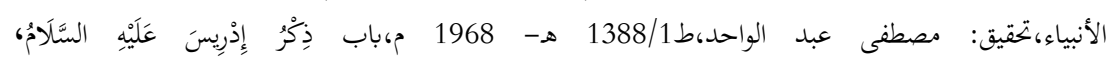

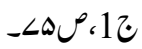

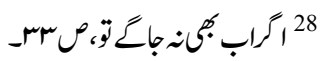

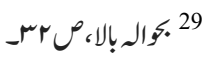

落

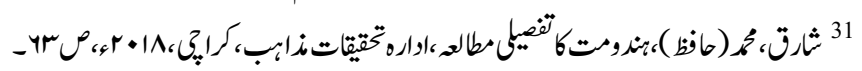

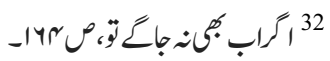

$$
\begin{aligned}
& \text { 33 بوالـ بالا، } 1472
\end{aligned}
$$

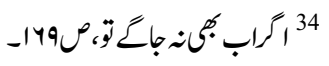

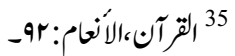

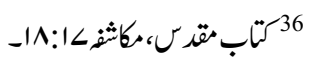

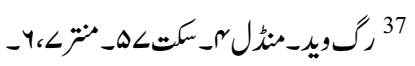

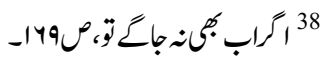

